\title{
Analyzing the Integrated Teaching of Theory and Practice in Communication Technology Based on the Cognitive Process
}

\author{
Xiaobiao Wu*, Hui Shi, Ying Zhang, Jing Tu \\ AF Rader NCO Academy, Wuhan 430000, Hubei Province, China \\ *Corresponding author: Xiaobiao Wu, Xiaobiao_wu@163.com
}

\begin{abstract}
This study analyzes the cognitive characteristics of students in communication courses in military colleges and the impact of integrated teaching of theory and practice on students' cognitive process as well as proposes the information processing model of students' cognitive process in the integrated teaching of theory and practice. Combining the cognitive characteristics of the students from Communication Technology, on the one hand, this study analyzes the five factors that affect the teaching effect of integrating theory and practice; on the other hand, it proposes improvement measures for the integration of theory and practice from the structure of the teaching content, teaching organization and management, modern education technology, and the ability of teachers.
\end{abstract}

Keywords: Integration of theory and practice; Cognitive process; Teaching reform

Publication date: December 2021; Online publication: December 23, 2021

\section{Introduction}

The purpose of communication courses in military academies is to enable students to master relevant theoretical knowledge within a certain period of time and to be able to manipulate professional equipment proficiently. The learning process is essentially a process of autonomous cognition. Whether it is a traditional teaching method or new teaching theory, based on the consideration of the objective laws of the cognitive process, the cognitive efficiency of students can be improved by intervening in the cognitive process. In order to improve the teaching effect by integrated teaching of theory and practice, teachers must understand the intervention process of the teaching methods on the cognitive process as well as rationally implement and stimulate the teaching methods pertaining to the integration of theory and practice. The benign intervention of students' cognitive process can maximize their learning efficiency. According to the particularity of the course content, such as communication courses in military colleges and universities, it is always impossible to combine theory and practice in the teaching objectives; in addition, its application effect is not as good in comparison to general courses. Based on this, this study begins from the characteristics of students' cognitive process, then analyzes the impact of the teaching methods pertaining to the integration of theory and practice on students' cognitive process as well as the rational application of integrated teaching of theory and practice, in order to improve the efficiency of the course teaching ${ }^{[1]}$.

\section{Basic theory of "cognitive process"}

Since ancient times, humans have begun to study and explore related theories of memory and thinking. For example, Confucius, a Chinese educator, had put forward the idea of "teaching without class" as early as two thousand years ago. Taking into consideration of different temperaments, interests, talents, and 
personality traits among students, and teaching students in accordance with their aptitudes, Confucius had "three thousand disciples and seventy-two wise men," which became a model for later generations.

By the mid-1950s, a psychological trend and research direction had emerged in the West. Cognitive psychology was one of the newest branches of psychology at that time, and it gradually became the main genre of western psychology in the 1970s. In a broad sense, it refers to the study of advanced human psychological processes, mainly cognitive processes, such as attention, perception, representation, memory, creativity, problem solving, speech, thinking, etc. Specifically, it is equivalent to contemporary information processing psychology; that is, the use of information processing viewpoints to study cognitive processes.

\subsection{Basic concept}

Cognitive process refers to the information processing process of individual cognitive activities. Cognitive psychology regards the cognitive process as a system of information processing according to a certain procedure, which is composed of a series of continuous cognitive operation stages, such as information acquisition, encoding (Encoding \& Coding), storage, extraction, and use.

The acquisition of information is the acceptance of stimulus information that directly affects the senses. The function of sensation is to obtain information. Information coding converts one form of information into another form of information to facilitate storage, extraction, and use of information. Individuals have corresponding information coding methods in cognitive activities, such as perception, representation, imagination, memory, and thinking. The storage of information is the preservation of information in the brain. In regard to memory activities, the storage of information takes many forms. The extraction of information is based on certain clues to find the needed information from the memory and take it out. The use of information refers to the use of the extracted information to perform cognitive processing on new information.

In the cognitive process, through the encoding of information, the characteristics of external objects can be transformed into information in the form of concrete images, semantics, or propositions and then stored in the brain. These concrete images, semantics, and propositions are actually the manifestations of the characteristics of external objects in an individual's psychology, and they are the reflection of objective reality in the brain. From the perspective of cognitive psychology, the objective laws of the cognitive process of the human brain are consistent, and people with similar experiences have higher degree of similarities in their cognitive processes. Understanding the objectiveness of the cognitive process among students, the integrated teaching of theory and practice can be used to improve the cognitive efficiency of students ${ }^{[2]}$.

\subsection{Cognitive process and characteristics of the students in military academies}

The most distinctive feature of the students in military academies is that they have long or short military work experience at the beginning of their enrollment. The military environment is relatively simple regardless of the job position. The environment, training, and education experience are roughly the same; therefore, their experience, logic of thinking, and learning goals are similar.

\subsubsection{Perception}

Perception is the most basic form of cognition for humans to understand the objective world ${ }^{[3]}$. The perception of students in military academies has the following characteristics: (1) sensitive and mature perception; junior college students in military academies are generally adults, and they are at the peak of their lives, in which their senses and perceptions are highly developed, and they have a keen sense of external things, especially military-related external objects; (2) a clear purpose of observation; due to the 
strong purpose of life training in the army, the students in military academies have a strong purpose of observing the surroundings; they are used to observing with the purpose of accomplishing the initial goal based on the observed facts.

\subsubsection{Thinking}

The students at this stage are very active in thinking and are gradually transitioning from formal logic to dialectical logic. Formal logic reflects the relative stillness of things and the definite boundaries between different things. Dialectical logic is a reflection of the unity of opposites to the essential connection of objective reality. The students' thinking ability is highly developed, where a meta-understanding of thinking is formed; that is, they can directly think about their own cognitive activities and realize their own cognitive activities as well as their methods of activities, which can allow deeper reflections on their own cognitive activities, emotional activities, and in understand the rules derived from the laws.

\subsubsection{Memory}

At this stage, the students' memory ability has significantly improved, where they can memorize on the basis of understanding the essence as well as analyze and synthesize familiar knowledge, especially for meaningful and valuable knowledge. Secondly, the quality of memory has fully developed. The memory of the students in military academies is agile and accurate, but its durability is poor. Most students do not have a good memory method, in which they only learn by rote or through physical exercises to help consolidate memory.

\subsection{Objective law of students' cognitive process}

Based on the above analysis and description of the cognitive process and cognitive characteristics of the students, combined with the cognitive process models established by different psychologists in the cognitive psychology theory, the information processing model in the cognitive process of the students in military academies is shown in Figure 1. The process of receiving information by the students is regarded as a product processing system, and the external information is the raw material. The purpose is to form long-term memory after inputting, processing, and storing external information, where attention distribution is the key to an efficient operation of each link ${ }^{[4]}$.

In the traditional teaching method of integrating theory and practice, the theoretical basis is generally spread through the teaching method, and then the demonstration method is used to enable the students to enter the information processing process 5, and finally through the practice method, it enables the students to repeat the information processing process 6 and the information processing process 5 . This method can indeed help students improve their learning effect; however, there are many shortcomings in the actual operation.

The first is that the professional staffs in military academies have a keen perception. The content organization level of the instructors and the level of classroom organization and management in the teaching process directly affect the operating efficiency of process 1 , which can easily cause the students to deviate, distract, and lose their subjective attention. The second is that the academic associates in military academies are slow in theoretical relevance, and it is difficult to combine current knowledge with past experience; thus, the information processing efficiency of process 4 is low. The third is pertaining to the information processing process 5 . The process of linking theory with practice is weak. Subjectively, students' temporary memory of theoretical knowledge would gradually disappear in the course of practice. Objectively, it is difficult for students to combine simple theoretical knowledge with complex ones as well as make connections between device technologies. 


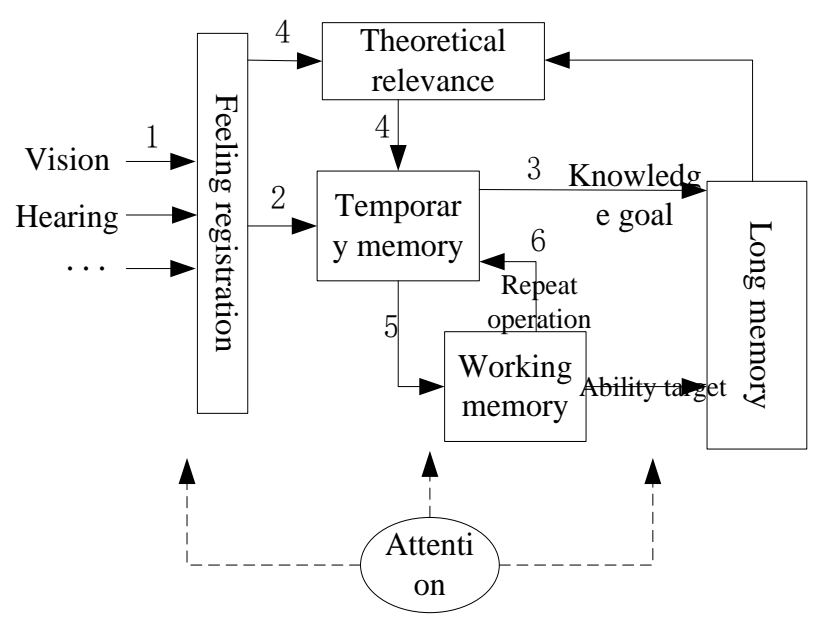

Figure 1. Information processing model in the cognitive process

The integration of theory and practice based on the cognitive process provides a new teaching idea. The application of "integration of theory and practice" in teaching refers to integrating theory with practice instead of combining theory with practice. From the perspective of cognitive psychology, the integration of theory and practice refers to the integration of theory and practice in every step of information processing in the cognitive process. Based on this idea, the basic theory of cognitive process can be used to analyze the shortcomings in the traditional integrated teaching of theory and practice.

\section{Analyzing the status of integrated teaching of theory and practice based on the cognitive process}

For communication courses in military academies, it is not the best choice to select a certain part of the course content for the teaching design of "integration of theory and practice." Judging from the current situation of integrated teaching of theory and practice, there are still many practical contradictions. These contradictions do not only include the contradiction of the content structure, but also between teachers and students, teaching goals and job requirements, etc. Combining with the current teaching status of communication courses in military academies, several prominent contradictions have been analyzed and studied.

\subsection{The teaching method is used bluntly}

In the integrated teaching of theory and practice, there is no in-depth study of the similarities and differences between integrated teaching of theory and practice with the previous theory combined with actual teaching. "Theory is lighter than practice" to the extreme of "respecting practice and lighter theory." From the perspective of the cognitive process theory, these methods can improve the efficiency of information processing in a certain part of the cognitive process, but the degree of improvement is restricted. For example, the talent training plan that determines the total class hours of the course cannot be changed. In order to use the teaching method of "integration of theory and practice," instructors need to reduce the time in order to explain other contents. It seems that theory is combined with practice, but in fact it is more difficult for students to gauge the teachers' thinking; thus, the learning efficiency does not rise but falls ${ }^{[5]}$.

\subsection{Weak teaching organization ability}

The application of the teaching method of "integration of theory and practice" puts forward great demands on the teaching organization ability of teachers. From the perspective of the cognitive process theory, the 
process by which students receive and process external information is extremely complex, and there are many intermediate links, which are interlocking. However, students are sensitive and easily affected by the external complex environment and reduce their attention to the content of the course. For example, communication courses in military academies generally adopt group teaching methods, which increases the difficulty in teaching, and students are more likely to face distractions and confusion. Therefore, the teachers' ability to organize teaching content and the ability of classroom personnel to organize are directly related to the efficiency of students' cognitive process. The degree and the number of repetitions would directly affect the cognitive process of students, Moreover, this process is not carried out step by step alike a theoretical class but needs to be adjusted in real time according to the specific situation of each classroom. This situation puts forward requirements for teachers' teaching content organization ability and the organization ability of classroom personnel. At present, most of the young faculty members are good at scientific research but lack the ability in teaching organization. Therefore, special training is required before the implementation of the "integration of theory and practice."

\subsection{Insufficient integration of teaching content with theory and practice}

According to the information processing model in the cognitive process, the information expressed subjectively by the instructors is not completely consistent with the information understood by the students upon processing. There are many reasons for this situation. The most important thing in the teaching process of integrating theory and practice is the integration of theory and practice, which requires careful arrangement of content by teachers.

Analyzing from the theory of cognitive psychology, there are two ways for students to receive information from the outside world. The first is to identify directly from the local characteristics to the overall characteristics of the information, while the second is based on previous knowledge. The received information is used for docking processing. In the cognitive process of students, both forms of information processing exist. However, due to the differences in the level of knowledge and the knowledge structure of the students themselves, there are huge differences when the students receive and process new information.

As a source of information, teachers should respect this difference in the course of teaching and try to reduce the impact of this difference through reasonable content organization as much as possible. However, most of the courses in the process of integrating theory and practice do not organize the teaching content carefully; only a simple combination of theory and practice is carried out. For example, in the teaching of communication courses in military academies, there are still theoretical and practical classes. Only some practical videos and pictures are included in theoretical classes, and only part of the theoretical review is conducted before practical classes. In that case, theory and practice are not closely integrated.

\subsection{Rigid motivation in learning, and poor learning atmosphere}

In junior military academies, communication courses are mainly offered to train students in using equipment proficiently, including equipment maintenance and proficient operation of equipment. However, due to the diversification of communication methods in modern society and a large reserve of spare communication equipment, unit leaders hardly expect the trainees to be able to maintain the equipment independently after graduation; rather, they pay more attention to their ability to operate the equipment. Therefore, most students are not interested in the theoretical aspect of military communication courses but are only interested in the operation of the equipment. This kind of thinking would gradually affect other students, resulting in the inactivity in classrooms and the clear expression that theoretical learning is meaningless. However, colleges are not training bases, and junior college students are not skilled workers. Therefore, reversing the mistaken learning motivation and creating a warm learning atmosphere are 
important ways to promote classroom efficiency and the cognitive process of students.

\subsection{Limited teaching conditions}

Insufficient teaching conditions are mainly reflected in two aspects. The first is insufficient class hours. The classroom interaction is not active. According to the cognitive process model, students will experience information processing process 4 and information processing process 5 in practical classes. These two processes are the only way to form key memories. However, whether it is the integration of new and old knowledge in the information processing process 4 or the process of integrating theory and practice in information processing process 5, it takes a lot of time for students. At the same time, there are outstanding man-machine contradictions. The number of students is far greater than the number of equipment. Even if group teaching is implemented, the teaching time still does not meet the needs. This is mainly reflected in the fact that it is often difficult for students to solve problems autonomously when they are practicing. No matter whether they are thinking by themselves or with the assistance of an instructor, there is no guarantee that they can complete a teaching task on time. Secondly, the practical environment is limited, and the students do not explore in an in-depth manner on their own. For example, the knowledge of signal processing in military communication courses is relatively abstract, in which students can only establish simple impressions through the teachers' descriptions, pictures, and videos; they are unable to visualize and develop intuitive impressions.

\section{Exploration of the teaching reform of the integration of theory and practice based on the cognitive process}

Cognitive psychology mainly studies the cognitive process of human beings. Its main feature is to emphasize the role of knowledge, in which knowledge is the main reason for determining human behavior. Students' cognitive structure and cognitive processing process directly determine their learning efficiency and learning results. Teaching organization, teaching content, and teaching environment would also indirectly affect students' learning. At the same time, the cognitive characteristics of the students in military academies must also be taken into consideration as they would objectively influence the teaching effect of the integration of theory and practice ${ }^{[6]}$. Based on the basic theory of cognitive process and the status quo of the teaching application of "integration of theory and practice," the application of the teaching method of "integration of theory and practice" and the applicability of the curriculum have been analyzed for the purpose of improving the teaching effect of integrating theory and practice. The following discusses the application of "integration of theory and practice" in communication courses of military colleges and universities from four aspects.

\subsection{Teaching reform based on the cognitive process}

In regard to the basic concept of cognitive process, the characteristics of cognitive process and the information processing process of the students in military colleges have been studied; in addition, the effect of integrated teaching of theory and practice on students' cognitive process has been analyzed. It has been proposed that the integrated teaching of theory and practice should not be a simple application of teaching methods.

Instead, the curriculum content should be sorted and reconstructed as a whole to adapt to the integrated teaching of theory and practice as well as provide a theoretical basis for the improvement of its teaching effect. For example, when implementing the integration of theory and practice to a course, the course content should be sorted and reconstructed first; then, theoretical knowledge and practical process should be rationally integrated on the basis of practical operations, so that both theory and practice exist in the 
students' sense at the same time.

Secondly, it is necessary to demonstrate the correlation between theoretical knowledge and cognitive experience as well as theoretical knowledge and practical skills while complementing the transitional content. Finally, a feedback process should be implemented to solve the cognitive differences due to individual differences and teach students in accordance with their aptitudes.

For example, additional equipment can be included in the practice platform, and the problems that are prone to occur during the operation can be stored as a memorandum in the form of texts and pictures. After several sessions, the memorandum would cover most of the problems encountered by the students during the operation. The description of the memorandum is based on the students as the main body. Instructors should guide the students to generalize and classify the problems as well as directly help them to solve the problems; this method helps students to develop a habit to actively think about problems and solve them.

\subsection{Moderately carry out psychological intervention}

In regard to the basic theory of cognitive process, attention is also an important factor that affects students' cognitive efficiency. Traditional teaching mainly focuses on external things to improve students' attention, such as multimedia, to stimulate their interest through fun activities. Cognitive psychology theory proposes that improving students' attention is actually an internal process, and the most direct impact is the students' learning motivation. Learning motivation generally refers to an individual's desire for a certain thing. When a person's learning motivation is relatively strong, there is often a burst of unexpected power, which includes physical power and spiritual power. The cognitive disharmony theory in cognitive psychology believes that when people have contradictory ideas, there will be a state of tension and conflicting cognitions are the driving force that forces the mind to seek or discover new cognitions. Psychology believes that students who complete this process ahead of time tend to be more successful. This kind of successful experience and sense of pleasure contribute to the formation of interest as well as produce a conscious and active attitude. Therefore, when designing the course, it is important to fully reveal the "fun" and value of a subject, guide the classroom knowledge in a direction that students are more interested in, as well as design knowledge points that contradict with daily life experience, such as combining information transmission rate with game network delay, questioning the transmission path of light, etc., in order to explore and understand the value of the course and stimulate the curiosity and thirst for knowledge among students. In addition, by setting up assessment links in the classroom, it is possible to heighten students' sense of success and satisfaction upon knowledge exploration. Subsequently, this would affirm their progress, improve their self-confidence, and stimulate their cognitive motivation.

\subsection{Improve the practical conditions for military communication courses}

Practical teaching is a necessary process for testing knowledge and deepening cognition. It is a process of input and output. It is also an effective way for students to consolidate theoretical knowledge and a necessary prop for the integrated teaching of theory and practice.

The transmission of information in communication courses is inherently intangible, especially the transmission of radio signals, which is even more difficult to figure out. In the course of practice, it is often necessary to combine the characteristics of the application to show its effect.

In traditional communication courses, multimedia animations and videos are often used to analyze simple communication theories, which can help students construct basic concepts, and to a certain extent, strengthen the sensory registration link of their cognitive process through visual formation of sensory registration. The practice process is different from the integrated practice process through movement, vision, and hearing. The sensory registration formed by the latter method is more intense. 
With technological progress, 3D equipment has been widely used in various industries. This can be seen in setting scenes through 3D equipment, visualizing invisible signals and signal processing processes, etc. All these can enhance students' intuitive experience and help students improve their cognition information processing efficiency.

\subsection{Improve teachers' understanding of "cognitive process"}

The integrated teaching of theory and practice requires teachers to fully consider the students' cognitive process and understand their thinking logic, so as to organically combine the logic and rhythm of lectures with the trainees' thinking, in order to achieve synchronization of teaching and learning.

This requires instructors to have a clear understanding of the students, courses, and themselves. Teachers need to understand the basic theory of cognitive process and master the degree to which the integrated teaching of theory and practice would affect the cognitive process of students, so that they can gauge the current state of the students through the reflection of the teaching process and grasp their teaching rhythm flexibly.

For example, in the process of group teaching, effectively organizing the learning of students who have not practiced and preventing the classroom environment from affecting the acquisition and processing of information are directly related to the organization and management ability of teachers as well as their ability in organization and teaching. For example, the "saturated" task is a good method. By assigning a large number of tasks to the students can help them think and learn actively.

\section{Conclusion}

Cognitive process emphasizes the information processing process and thinking logic of students in learning. It studies and analyzes students as the main body in receiving information and provides theoretical basis as well as practical inspiration for the teaching reforms of the "integration of theory and practice." Cognitive process proposes that the learning process of students is the process of information processing, and the use of integrated teaching of theory and practice produces a positive influence by intervening in this process. Therefore, research from the perspective of the application of integrated teaching of theory and practice on the cognitive process reveals a deeper connection between teaching and learning. Starting from the learners' acquired psychology and cognitive laws, the integrated teaching of theory and practice adopts the unity of teaching and learning, which is of great benefit to effectively control the teaching process and improve the cognitive ability of students.

\section{Disclosure statement}

The authors declare that there is no conflict of interest.

\section{References}

[1] Wu S, Ma ZY, Hu QY, 2020, The Exploration of Electronic Technology Teaching under the Integration Mode of Theory and Practice. Education and Teaching Forum, 32: 282-284.

[2] Pan WJ, 2011, Research on the Teaching Reform of Logistics Specialty Based on Cognitive Psychology. Lifting and Transporting Machinery, 12: 42-47.

[3] Yang QG, Yi ZJ, 2004, Looking at University Teaching Methods from the Cognitive Process of University Students. Journal of Chongqing Jiaotong University (Social Science Edition), 02: 135-136, 139. 
[4] Song JS, 2010, Research on Teaching Methods Based on the Analysis of the Cognitive Process of Students. Journal of Jimei University (Educational Science Edition), 02: 72-75.

[5] Zhou B, Zhou GJ, Zhao DM, 2020, The Teaching Practice of the Integration of Theory and Practice in the Course of Digital Circuits. Eldectronic Production, 12: 60-61, 63.

[6] Yang J, 2019, Higher Vocational Mathematics Education Reform Based on Students' Cognitive Process. Journal of Huainan Vocational and Technical College, 19(03): 79-80. 